\title{
Structured fiber supports for gas phase biocatalysis
}

\author{
Takoua Debeche ${ }^{\mathrm{a}, *}$, Cynthia Marmet $^{\mathrm{a}}$, Lioubov Kiwi-Minsker ${ }^{\mathrm{b}}$, Albert Renken $^{\mathrm{b}}$, \\ Marcel-Alexandre Juillerat ${ }^{\mathrm{a}}$ \\ a Department of Food Science, Vers-chez-les-Blanc, Nestlé Research Center, \\ P.O. Box 44, CH-1000, Lausanne 26, Switzerland \\ ${ }^{\mathrm{b}}$ Swiss Federal Institute of Technology, Lausanne, CH-1015, Switzerland
}

Received 20 August 2004; received in revised form 22 December 2004; accepted 9 January 2005

\begin{abstract}
Pseudomonas cepaciae lipase adsorbed onto non-porous structured fiber supports in the form of woven fabrics, was used to catalyze hydrolysis and transesterification reactions in the gas phase. The enzyme adsorbed onto carbon fiber support exhibited much higher catalytic activity compared to the enzyme immobilized onto glass fiber carrier. The effect of temperature and relative humidity on reactions catalyzed by P. cepaciae lipase adsorbed onto structured fiber carbon support was studied in the gas system. Under the conditions investigated (up to $60^{\circ} \mathrm{C}$ and $80 \%$ relative humidity), the immobilized enzyme showed a high thermostability and could be efficiently used to catalyze hydrolytic and transesterification reactions in continuous mode. Structured fiber supports, with a high specific surface area and a high mechanical resistance, showed a low-pressure drop during the passage of reactants through a reactor. The approach proposed in this study could be suitable for immobilization of a wide variety of enzymes.
\end{abstract}

(C) 2005 Elsevier Inc. All rights reserved.

Keywords: Lipase; Immobilization; Structured fiber support; Gas phase; Hydrolysis; Transesterification

\section{Introduction}

Most of the "natural" flavor compounds used by the food and fragrance industry are obtained by extraction from natural sources, e.g. plants. However, low yields, decreasing and variable availability of certain natural sources due to climatic instability have stimulated large investigations to produce flavors in controlled biotechnological processes. Among these biotechnologies, solid-gas biocatalysis has been identified as one of the most promising approach to synthesize aroma volatile compounds [1]. The bioprocess is characterized by the fact that enzymes or intact cells are in a solid form (totally or partially dehydrated) and the reactants are in the gaseous state $[2,3]$.

Solid-gas biocatalysis has been shown to offer the following advantages over solid-liquid systems: (1) immobilization of the biocatalyst is more simple; and (2) its

\footnotetext{
* Corresponding author. Tel.: +41 2178587 38; fax: +41 217858554 .

E-mail address: takoua.debeche-boukhit@rdls.nestle.com (T. Debeche).
}

thermo-denaturation is limited since it is (partially) dehydrated; (3) mass transfer is more efficient in the gas phase and therefore; (4) production of by-products is reduced or avoided; (5) products and unconverted substrates can be easily recovered by condensation. Furthermore, (6) the risk of microbial contamination is much lower [4]. Significant progress has been achieved during the last few years in the understanding of the mechanisms of solid-gas biocatalysis and a pilot-scale process has been recently reported [5].

Solid-gas biocatalysis can be carried out by either nonsupported or immobilized biocatalysts. Non-supported enzymes display stability and activity optima when they have a complete first hydration layer. At higher water activities, denaturation and aggregation of the catalyst might occur. In order to minimize aggregation of the enzyme that can lead to a loss of activity and a decreased stability, adsorption techniques have been carried out [6]. Immobilization by physical adsorption is easy and cheap, and it is a very convenient protocol for gas phase biocatalysis since there is no desorption of the protein from the carrier. Porous supports are the most 
widely used because they allow the binding of high protein amounts. But enzyme adsorbed in the pores of a support may exhibit a lower catalytic activity as compared to free enzyme due to a disruption of the protein conformation [7]. The texture of the carrier also influences the biocatalytic reaction: non-porous materials limit the diffusion constraints [8], while fibrous carriers provide easy passage of gas through the biocatalytic bed [9]. The hydrophilic/hydrophobic character of the support is also an important parameter to consider. Hydrophobic supports are preferred in solid-gas bioprocesses because their interaction with water remains very low even at high water activities. Many hydrophobic materials have been used to immobilize lipases since the large hydrophobic pocket surrounding the catalytic site of lipases can easily interact with hydrophobic solid supports [10]. Such adsorbed lipases have been shown to display a hyperactivation due to interfacial activation promoted by the hydrophobic surface of the support [11].

Structured fiber supports in the form of fabrics offer many advantages compared to classical catalytic beds: their opened macrostructure allows high flow rates with low-pressure drop, mass transfer is more efficient, they have a high surface/volume ratio, and the scale-up is facilitated. In our view, such carriers may be useful to develop bioprocesses in liquidorganic and solid-gas phases. Most of the studies aiming at comparing the effect of the support on enzyme immobilization and activity were achieved with non-woven materials, e.g. powders [12], glass beads [13], glass fibers [9], glass wool [14], nylon fibers [15], and polymeric materials in membrane form [10]. Limited studies report the use of structured supports for enzyme immobilization and very few works are dealing with the effect of the texture of the support [7]. Structured fiber supports have been recently proposed as chemical catalysts [16].

To overcome these shortcomings, we investigated the effect of two different structured fiber supports, a glass fiber support (GFS) and a carbon fiber support (CFS), on solid-gas reactions catalyzed by Pseudomonas cepaciae lipase (lipase PS). The carbon fiber support, which gave the better results, was then used to study the effects of temperature and relative humidity on lipase activity in the gas phase.

\section{Materials and methods}

\subsection{Chemicals and enzymes}

Lipase PS (from P. cepaciae) was purchased from Amano (Chipping Norton, England). All the chemicals were purchased from Fluka (Buchs, Switzerland) and were of high purity (99\%).

\subsection{Structured fiber supports}

The glass support used in this work was a woven fabric made of glass fibers (type-E), obtained from Vetrotex S.A.

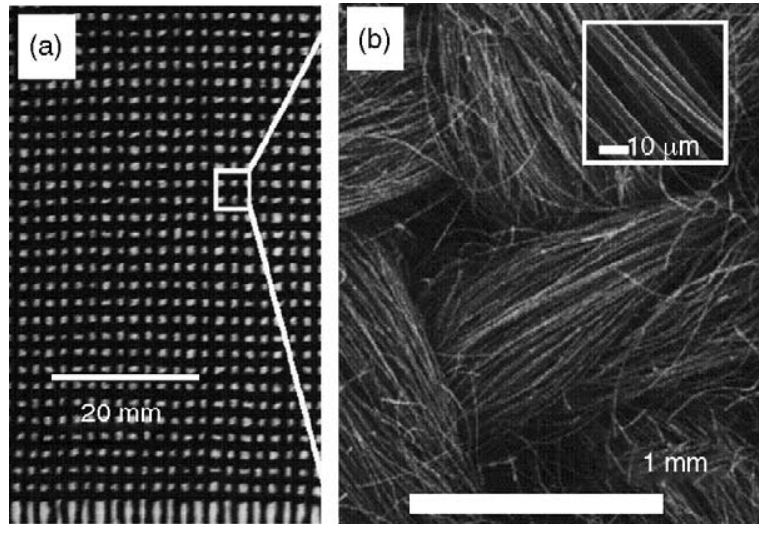

Fig. 1. Characterization of carbon fiber textile: (a) general view; (b) scanning electron micrograph showing elemental fibers.

(Saint-Gobin, France). It is an aluminoborosilicate material with a specific surface area of about $2 \mathrm{~m}^{2} \mathrm{~g}^{-1}$. The GFS was chosen because glass in the form of beads is commonly used to immobilize proteins.

A carbon woven fabric with polyurethane sizing (HTS 5631 from Tenax Fiber GmbH, Germany) was also used (Fig. 1). The CFS was chosen because it is resistant to mechanical and heat stress.

Both GFS and CFS were cut into pieces (circles, $15 \mathrm{~mm}$ diameter) and packed into the reactor.

\subsection{Adsorption of lipases onto structured supports}

The lipase PS used in this study contained Celite ${ }^{\circledR}$ that needed to be removed. The Celite ${ }^{\circledR}$ was extracted from the commercial enzyme preparations as follows: $3.5 \mathrm{~g}$ of the commercial powder were dissolved in $50 \mathrm{ml}$ milli-Q water. The solution was then stirred for $60 \mathrm{~min}$ at $4{ }^{\circ} \mathrm{C}$ and centrifuged ( $5 \mathrm{~min}, 3500 \mathrm{rpm}$ ). The pellet was re-suspended in $50 \mathrm{ml}$ of sodium phosphate buffer $(50 \mathrm{mM}, \mathrm{pH} 7)$ and the operation was repeated. The two supernatants were pooled and filtered $(0.20 \mu \mathrm{m}$ filter $)$ and the volume was completed to $150 \mathrm{ml}$ with sodium phosphate buffer $(50 \mathrm{mM}, \mathrm{pH} 7)$. Lipase adsorption onto selected supports was carried out overnight by incubating $1 \mathrm{~g}$ support (several circular pieces of support, $15 \mathrm{~mm}$ diameter) with $50 \mathrm{ml}$ of supernatant at $4{ }^{\circ} \mathrm{C}$ with gentle stirring. The supports were then washed with milli-Q water and air dried overnight at room temperature. The immobilized enzymes were stored at $4{ }^{\circ} \mathrm{C}$ in a desiccator over silica gel. The total protein content of the different fractions were measured using Lowry's procedure [17]. The amount of protein adsorbed onto the support was calculated from the difference in protein concentrations of the original solution and of the wash solution. This amount varied in the range of $1-20 \mathrm{mg}$ protein per gram of fabric depending on its nature. After drying, the pieces of support with the chosen quantities of lipase were packed into the reactor. 


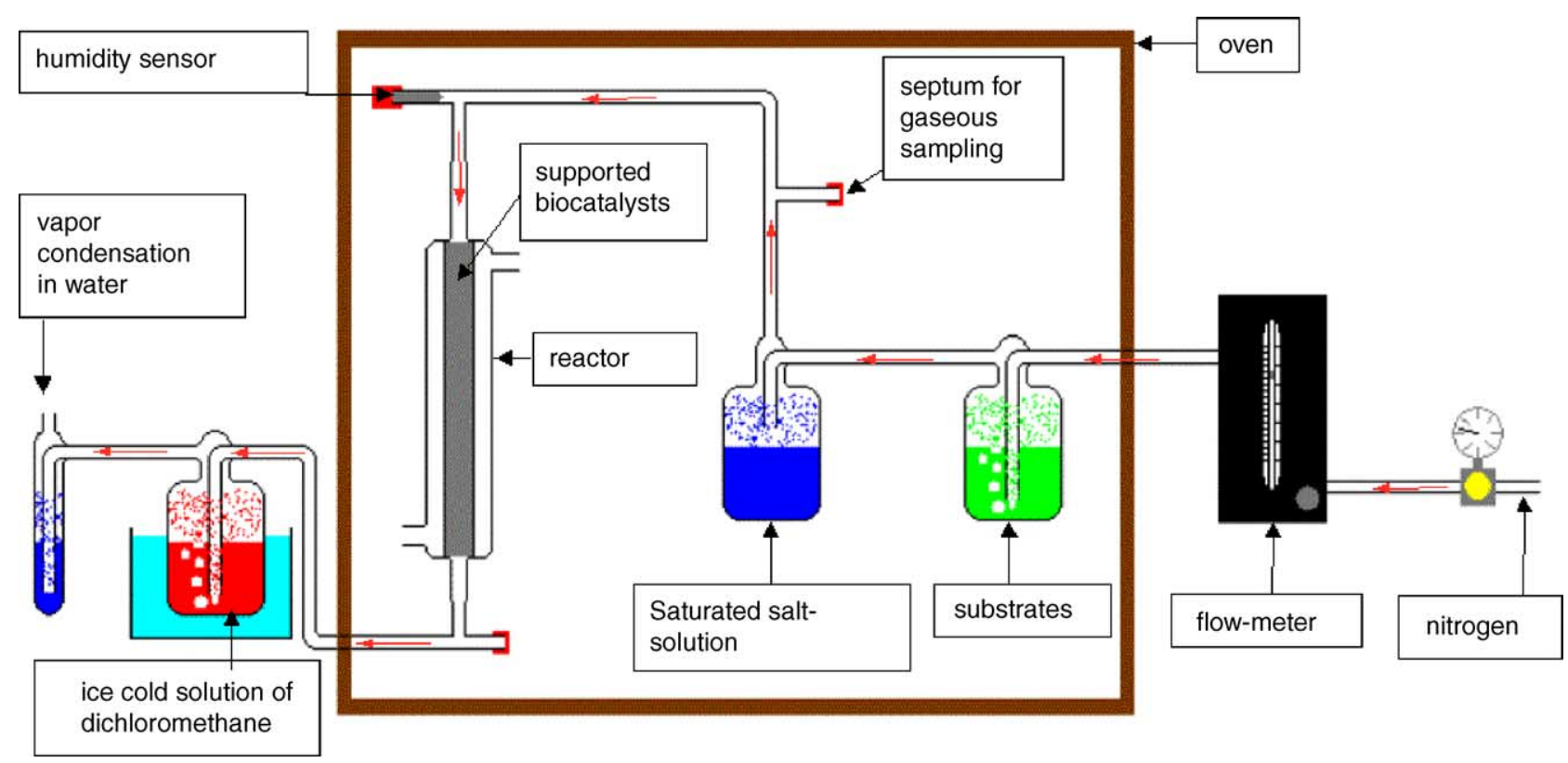

Fig. 2. Schematic diagram of the laboratory scale solid-gas bioreactor.

\subsection{Enzymatic assay}

Enzymatic activity of lipase PS solutions (before and after adsorption onto the supports) was determined using a colorimetric assay based on the hydrolysis of $p$-nitrophenyl acetate (pNPA), and the amount of lipase units adsorbed onto the carriers was estimated by subtraction. The lipase activity was determined using a modification of the method described by O'Connell and Varley [18]. One international unit of enzyme (IU) was defined as the amount of enzyme that liberated $1 \mu \mathrm{mol}$ of pNP per minute.

\subsection{Laboratory scale setup for solid-gas catalysis}

A continuous solid-gas bioprocess functioning under atmospheric pressure was developed at a laboratory scale (Fig. 2). The reactor was a cylindrical glass column (working volume $20 \mathrm{ml}$ ) filled with the immobilized enzymes. Nitrogen was used as the carrier gas and relative humidity in the system was controlled by the use of saturated salt-solutions. Nitrogen flow rate through the flasks containing the substrates was set at $80 \mathrm{ml} / \mathrm{min}$ with a flowmeter. A mean residence time of $15 \mathrm{~s}$ was calculated for standard temperature and pressure. The reaction products were trapped into an ice-cold solution of dichloromethane containing an internal standard (valeric acid). Samples were taken at regular intervals and analyzed by gas chromatography. The whole installation except the recovery flask was placed in an incubator to control the temperature and to avoid condensation. All the lines were made of tetrafluoroethylene (TFE) tubing $(3.18 \mathrm{~mm} \times 2.54 \mathrm{~mm}$, o.d. $\times$ i.d. $)$ and all the flasks were in glass. The gas phase entering and leaving the reactor was withdrawn by a $5 \mathrm{ml} \mathrm{Gastight}{ }^{\circledR}$ syringe (Hamilton, Switzerland) and analyzed by gas chro- matography. Relative humidity $\left(H_{\mathrm{R}}\right)$ of the gas mixture before and after the reactor was measured using a humidity sensor (Hygroclip SC04, Rotronic AG, Switzerland). The solutions used to control relative humidity consisted of water saturated with $\mathrm{LiCl}, \mathrm{Mg}\left(\mathrm{NO}_{3}\right)_{2}, \mathrm{NaCl}$ and $\mathrm{KNO}_{3}$, which provided relative humidities at $60{ }^{\circ} \mathrm{C}$ of $11,42,74$ and $80 \%$, respectively. All the reaction rates were measured in steady state conditions. Mass balances were checked for each reaction run.

\subsection{Chromatographic analysis}

Gas chromatography (GC) analyses were performed using an Agilent 6890 Series GC equipped with a Splitless injector and a flame ionization detector (FID). Separation of volatiles was achieved on a DB-Wax column $(30 \mathrm{~m} \times 0.25 \mathrm{~mm}$, film thickness $0.25 \mathrm{~mm}$, J\&W Scientific) using helium as carrier gas $(1.5 \mathrm{ml} / \mathrm{min}$ in the column). Hydrogen and air were supplied to the FID at 40 and $400 \mathrm{ml} / \mathrm{min}$ respectively. The temperature program was as follows: $10 \mathrm{~min}$ isothermal at $15^{\circ} \mathrm{C}$, then raised to $220^{\circ} \mathrm{C}$ at $5^{\circ} \mathrm{C} / \mathrm{min}$. The injector and the detector were kept at 220 and $250^{\circ} \mathrm{C}$, respectively. For samples in dichloromethane, valeric acid was used as internal standard. For vapor phase analysis, samples in the Gastight ${ }^{\circledR}$ syringe were manually injected in the split injector.

\section{Results and discussion}

\subsection{Adsorption of lipase PS onto solid fibrous supports}

Immobilization of lipase PS onto both GFS and CFS was shown to follow a first order kinetic, with more than $90 \%$ enzyme immobilized after $6 \mathrm{~h}$. This mild adsorption procedure 
has permitted to obtain a supported biocatalyst that showed no significant loss of activity after at least 5 successive runs (data not shown). Furthermore, the enzyme could be easily desorbed in aqueous media and recovered from the two types of supports tested, and the structured supports could be reused because of their high mechanical, thermal and chemical stability.

\subsection{Mass transfer limitations}

Mass transfer in the gas phase is more efficient than in solution since gases are characterized by low viscosities and high diffusion coefficients. Internal transfer limitations were assessed by investigating the effect of the amount of lipase PS adsorbed onto glass support on the rate of ethyl acetate hydrolysis at $60^{\circ} \mathrm{C}$ and at $74 \%$ relative humidity. Our results showed that the reaction rates were proportional to the enzymatic activity (enzymatic activity ranged from 1000 to $4800 \mathrm{IU}$, as determined with the pNPA assay). Thus the reaction rate was shown not to be limited by internal mass transfer limitations.

No external substrate diffusional limitations occurred since the reaction rate remained constant over the range of flow rate from 40 to $80 \mathrm{ml} / \mathrm{min}$.

\subsection{Effect of support properties on ethyl acetate hydrolysis catalyzed by adsorbed lipase PS}

As can be seen on Fig. 3, the reactor needed between 2 and $5 \mathrm{~h}$ to be stabilized, depending on the working $H_{\mathrm{R}}$ and on the type of support. This stabilization phase was due to the equilibration of the temperature and the relative humidity in the reactor, as well as to the equilibration of the hydration state of the biocatalyst. Transient phases varying from 1 to $13 \mathrm{~h}$ have been reported depending on the bioprocess setup $[2,3]$.

Fig. 3 shows that the reaction rate of ethyl acetate hydrolysis was about 10 times higher when the lipase PS was adsorbed onto CFS compared to GFS. Both structured supports

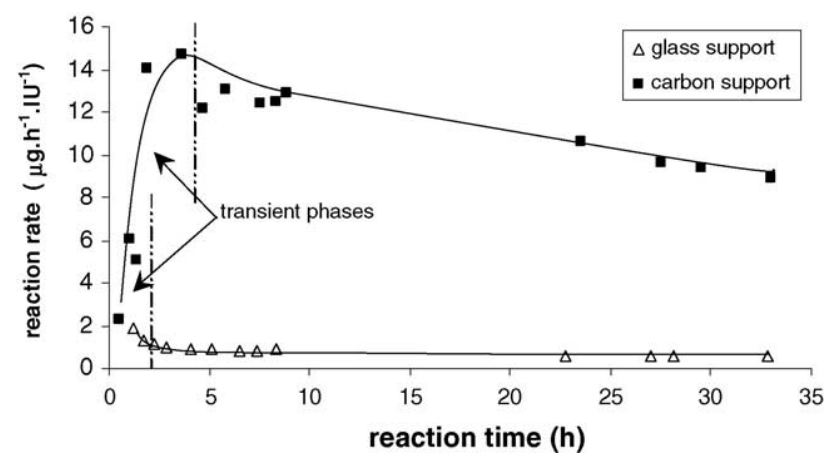

Fig. 3. Effect of the support type on the hydrolysis of ethyl acetate in the gas phase. Hydrolysis of ethyl acetate was performed by immobilized lipase PS (2200 IU onto $1.5 \mathrm{~g}$ of support). Reactions were carried out at $60^{\circ} \mathrm{C}$ at $74 \% H_{R}$. Reaction rate is expressed in $\mu \mathrm{g}$ of acetic acid produced per hour and per IU of enzyme. have close specific surface area $\left(2 \mathrm{~m}^{2} \mathrm{~g}^{-1}\right)$ but differ in their hydrophilic/hydrophobic properties. The glass fibers being highly hydrophilic while the carbon fibers are hydrophobic. Our results could be explained by the fact that adsorption onto the CFS involved the hydrophobic pocket around the active site, leaving the catalytic center free. Furthermore, previous works have shown that immobilization of lipases onto hydrophobic supports lead to hyperactivation via interfacial adsorption $[11,19,20]$. Another explanation could be a more favorable adsorption of ethyl acetate by carbon fibers as compared to glass fibers. Measurements of equilibrium constants of the reaction for the two supports and isotherm sorption curves with ethyl acetate would be needed to confirm this hypothesis.

\subsection{Effect of temperature and relative humidity on ethyl acetate hydrolysis catalyzed by lipase PS adsorbed onto carbon fiber support}

In the gas phase reactor, the streams were controlled for $H_{\mathrm{R}}$ rather than organic vapor concentrations. Therefore, initial substrate concentrations varied when changing the temperature or $H_{\mathrm{R}}$ and comparison on the basis of initial rates was not possible [21]. As a result, all reaction rates were measured under steady-state conditions.

Fig. 4 shows that at $74 \% H_{R}$, maximal ethyl acetate hydrolysis occurred at $60^{\circ} \mathrm{C}$. In terms of thermostability, the lipase did not show any loss of activity at both 30 and $45^{\circ} \mathrm{C}$ after $33 \mathrm{~h}$ continuous work at $74 \% H_{\mathrm{R}}$. In contrast, the reaction rate at $60^{\circ} \mathrm{C}$ decreased by $20 \%$ after $33 \mathrm{~h}$. These results are in line with the assumption that dry enzymes are more thermostable [4].

The effect of water content on enzyme stability is presented on Fig. 5. It was shown that for a constant temperature, acetic acid production increased with an increase in relative humidity. However, for the highest humidity, the production was decreased by $14 \%$ after $33 \mathrm{~h}$ reaction time. Thus, as it

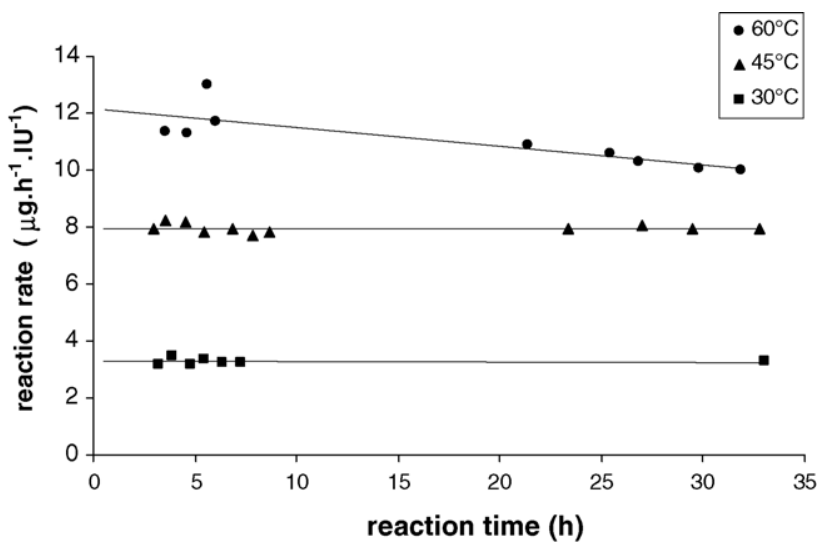

Fig. 4. Effect of temperature on the hydrolysis of ethyl acetate in the gas phase. Reaction rate is expressed in $\mu \mathrm{g}$ of acetic acid produced per hour and per IU of enzyme. Reactions were carried out at $74 \%$ relative humidity, with $4500 \mathrm{IU}$ of lipase PS immobilized onto $1.5 \mathrm{~g}$ of carbon fiber support. 


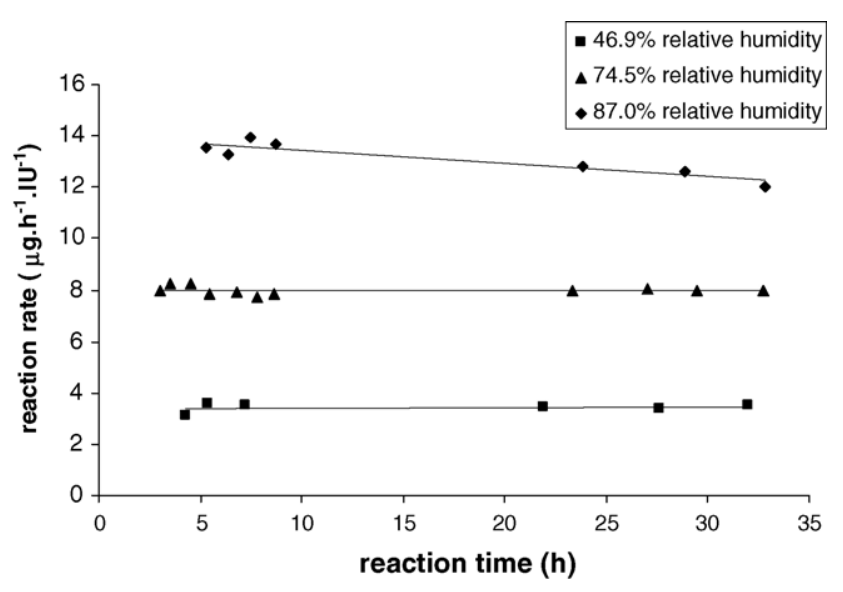

Fig. 5. Effect of relative humidity on the hydrolysis of ethyl acetate in the gas phase. Reactions were carried out at $45^{\circ} \mathrm{C}$, with $4500 \mathrm{IU}$ of lipase PS immobilized onto $1.5 \mathrm{~g}$ of carbon fiber support. Relative humidity of the gas phase was controlled by saturated salt-solutions as described in Section 2.

has been shown in previous reports dealing with gas phase biocatalysis, water has a negative effect on lipase stability but a positive effect on activity $[2,4]$. Furthermore, in the case of hydrolysis, the reaction rate is favored at high $H_{\mathrm{R}}$.

\subsection{Transesterification between vinyl acetate and n-propanol catalyzed by lipase PS adsorbed onto carbon fiber support}

Transesterification was catalyzed by lipase PS in the gas phase. The advantage of this reaction is that water does not participate in the reaction. Furthermore, the transesterification is irreversible because of the tautomerisation of vinyl alcohol into acetaldehyde. This reaction was carried out at low $H_{\mathrm{R}}$ in order to avoid vinyl acetate hydrolysis. Two separated flasks containing vinyl acetate and $n$-propanol were used. The two vapor streams mixed into one stream and passed through the flask containing a saturated salt solution before entering the reactor containing the immobilized enzyme.

As can be seen from Fig. 6, relative humidity had low effect on the reaction yield at both 30 and $45^{\circ} \mathrm{C}$. In contrast, the reaction yield of the transesterification carried out at $60{ }^{\circ} \mathrm{C}$ was higher at $0 \% H_{\mathrm{R}}$ as compared to $11 \% \mathrm{H}_{\mathrm{R}}$. This can be easily explained by a greater thermo-denaturation of the enzyme at $60^{\circ} \mathrm{C}$ and at high water content. Another explanation could be an inhibition of the enzyme due to production of acetic acid. Indeed, the production of acetic acid resulting from hydrolysis of either vinyl acetate or the newly formed propyl acetate was detected when the reaction was carried out at $11 \% H_{\mathrm{R}}$. A mass balance performed on the reactants revealed that the molar yield of acetic acid accounted for about $6-13 \%$ of the initial propanol concentration depending on the temperature. Similar results were reported with vinyl acetate/isoamyl acetate transesterification [21].

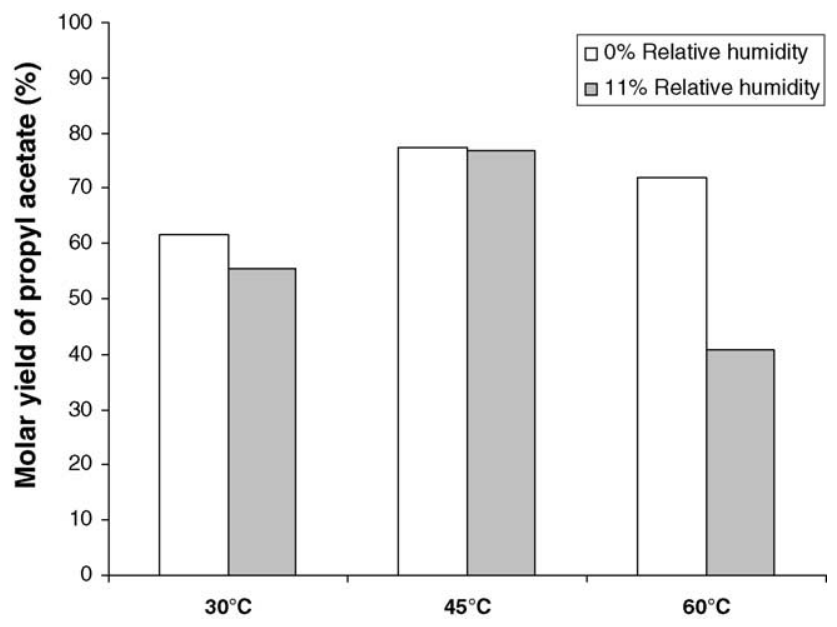

Fig. 6. Effect of temperature and relative humidity on the transesterification between vinyl acetate and $n$-propanol in the gas phase. Molar yield is expressed as propyl acetate production in percentage of the initial concentration of $n$-propanol. The water content of the gas phase was controlled by saturated salt-solutions as described in Section 2. Experimental conditions: $24 \mathrm{~h}$ reaction time, $7000 \mathrm{IU}$ of lipase PS adsorbed onto $1.5 \mathrm{~g}$ of CFS at $0 \%$ $H_{\mathrm{R}}$ and $11,000 \mathrm{IU}$ of lipase PS adsorbed onto $1.5 \mathrm{~g}$ of CFS at $11 \% H_{\mathrm{R}}$.

\section{Conclusion}

This study reports for the first time the use of enzymes immobilized onto structured fiber supports to carry out gas phase biocatalysis. Two structured fiber supports offering different hydrophilic/hydrophobic characteristics, combined with high mechanical resistance and low-pressure drop, were used as carrier for the immobilization of $P$. cepaciae lipase. The lipase immobilized onto carbon fiber support exhibited the highest activity as compared to its immobilization onto glass fiber carrier. This result confirms that immobilization of lipases onto solid hydrophobic surfaces promotes interfacial activation. Structured fiber supports in the form of woven fabrics are promising materials for immobilization of enzymes to perform solid-liquid and solid-gas biocatalysis.

\section{References}

[1] Barzana E, Klibanov AM, Karel M. Enzyme-catalyzed, gas-phase reactions. Appl Biochem Biotechnol 1987;15:25-34.

[2] Parvaresh FRH, Thomas D, Legoy MD. Gas phase transesterification reactions catalyzed by lipolytic enzymes. Biotechnol Bioeng 1992;39:467-73.

[3] Maugard T, Lamare S, Legoy MD. Gas phase biotransformation reaction catalyzed by baker's yeast. Biotechnol Bioeng 2001;73:164-8.

[4] Lamare S, Legoy MD. Biocatalysis in the gas phase. Trends Biotechnol 1993;11:413-8.

[5] Lamare S, Caillaud B, Roule K, Goubet I, Legoy MD. Production of natural esters at the pre-industrial scale by solid/gas biocatalysis. Biocatal Biotransform 2001;19:361-77.

[6] Lamare S, Legoy MD. Solid/gas biocatalysis: how to fully define the system? Biotechnol Tech 1995;9:127-32.

[7] Mas'ko AA, Morozova AA, Lyga LK, Galushko NA. Immobilization of trypsin on carbon-fiber carriers differing in texture, porosity, and surface chemistry. Appl Biochem Microbiol 1992;28:162-6. 
[8] Wu C-W, Lee J-G, Lee W-C. Protein and enzyme immobilization on non-porous microspheres of polystyrene. Biotechnol Appl Biochem 1998;27:225-30.

[9] Toldrá F, Jansen NB, Tsao GT. Hydrolysis of maltose and cornstarch by glucoamylase immobilized in porous glass fibres and beads. Process Biochem 1992;27:177-81.

[10] Balcao VM, Vieira MC, Malcata FX. Adsorption of protein from several commercial lipase preparations onto a hollow-fiber membrane module. Biotechnol Prog 1996;12:164-72.

[11] Fernandez-Lafuente R, Armisen P, Sabuquillo P, Fernandez-Lorente G, Guisan JM. Immobilization of lipases by selective adsorption on hydrophobic supports. Chem Phys Lipids 1998;93:185-97.

[12] Pencreach G, Baratti JC. Activity of Pseudomonas cepacia lipase in organic media is greatly enhanced after immobilization on a polypropylene support. Appl Microbiol Biotechnol 1997;47:630-5.

[13] Gunnlaugsdottir H, Wannerberger K, Sivik B. Alcoholysis and glyceride synthesis with immobilized lipase on controlled-pore glass varying hydrophobicity in supercritical carbon dioxide. Enzyme Microb Technol 1998;22:360-7.

[14] Barton JW, Reed EK, Davison BH. Gas-phase enzyme catalysis using immobilized lipase for ester production. Biotechnol Tech 1997;11:747-50.
[15] Braun B, Klein E. Immobilization of Candida rugosa lipase to nylon fibers using its carbohydrate groups as the chemical link. Biotechnol Bioeng 1996;51:327-41.

[16] Kiwi-Minsker L, Yuranov I, Holler V, Renken A. Supported glass fibers catalysts for novel multi-phase reactor design. Chem Eng Sci 1999;54:4785-90.

[17] Lowry OH, Rosebrough NH, Farr AL, Randall RF. Protein measurement with Folin phenol reagent. J Biol Chem 1951;193:265-73.

[18] O'Connell PJ, Varley J. Immobilzation of Candida rugosa lipase on colloidal gas aphrons (CGAs). Biotechnol Bioeng 2001;74(3):264-9.

[19] Palomo JM, Munoz G, Fernandez-Lorente G, Mateo C, FernandezLafuente R, Guisan JM. Interfacial adsorption of lipases on very hydrophobic support (octadecyl-Sepabeads): immobilization, hyperactivation and stabilization of the open form of lipases. J Mol Catal Part B 2002;19-20:279-86.

[20] Bastida A, Sabuquillo P, Armisen P, Fernandez-Lafuente R, Huguet J, Guisan JM. A single step purification, immobilization, and hyperactivation of lipases via interfacial adsorption on strongly hydrophobic supports. Biotechnol Bioeng 1998;58:486-93.

[21] Cameron PA, Davison BH, Frymier PD, Barton JW. Direct transesterification of gases by "dry" immobilized lipase. Biotechnol Bioeng 2002;78:251-6. 